\title{
A percepção dos moradores da Mesorregião Metropolitana de Belém em isolamento social em virtude da pandemia.
}

\section{The perception of residents of the Metropolitan Mesoregion of Belém in social isolation as a virtue of the pandemic.}

\author{
Jonathan Dias Marques ${ }^{1 *}$, Gustavo Batista Borges ${ }^{1}$, Victor Henrique Rodrigues Dias ${ }^{1}$, \\ Thamyres de Souza Aguiar1 ${ }^{1}$ Italo Marlone Gomes Sampaio², Vânia Silva de Melo
}

\begin{abstract}
RESUMO
No fim de 2019 a humanidade foi surpreendida com um novo coronavírus, transmissor da COVID-19, promovendo posteriormente o isolamento social. A educação ambiental nesse período faz-se de suma importância, pois além de contribuir com a sustentabilidade, diminui possíveis transtornos ao ser humano. Diante disso, foi realizada uma pesquisa com os moradores da Mesorregião Metropolitana de Belém, sobre a percepção ambiental no período pandêmico, contendo algumas perguntas sobre a produção de resíduos, coleta seletiva, poluição e políticas públicas, além de questionamentos específicos como "Quais resíduos foram mais produzidos por você nesse período de isolamento social?", foram contabilizados o total de 524 questionários respondidos dentro 7 cidades escolhidas na região. Os resultados obtidos demonstram que na visão dos participantes a produção de resíduos aumentou nesse período, sendo que uma parcela um pouco maior da população não faz coleta seletiva, além disso os resíduos orgânicos e materiais plásticos foram os mais produzidos nesse período.
\end{abstract}

PALAVRAS-CHAVE: Isolamento social; Educação Ambiental; Sustentabilidade;

\begin{abstract}
At the end of 2019, humanity was surprised with a new coronavirus, transmitter of COVID-19, later promoting social isolation. Environmental education in this period is of paramount importance, as in addition to contributing to sustainability, it reduces possible inconvenience to human beings. Therefore, a survey was carried out with the residents of the Metropolitan Mesoregion of Belém, about the environmental perception in the pandemic period, containing some questions about the production of waste, selective collection, pollution and public policies, as well as specific questions such as "What waste were produced by you in this period of social isolation?", a total of 524 questionnaires answered in 7 cities in the region were counted. The results obtained demonstrate that, in the view of the participants, the production of waste increased during this period, with a slightly larger portion of the population not doing selective collection, in addition to organic waste and plastic materials being the most produced in this period.
\end{abstract}

Keywords: Social isolation; Environmental education; Sustainability;

\footnotetext{
1 Universidade Federal Rural da Amazônia - UFRA.

* jonathandiasmarques.2015@gmail.com

${ }^{2}$ Secretaria de Estado desenvolvimento Agropecuário e da pesca-SEDAP
} 


\section{INTRODUÇÃO}

No final de dezembro de 2019, a Organização Mundial da Saúde (OMS) foi notificada sobre o aumento de casos de pneumonia na cidade Wuhan, na China, e posteriormente constatou que se tratava do novo coronavírus (SARS-coV-2), transmissor

da COVID-19 (OPAS, 2020), fazendo com que a sociedade entrasse em isolamento social. Nesse contexto, é necessário que a população seja alertada sobre as práticas ambientais exploratórias e assumindo algumas responsabilidades sustentáveis (SILVA et al., 2020).

O ser humano ao longo dos anos está cada vez mais explorando os recursos ambientais e contribuindo para a crise ambiental, tendo a produção em massa de resíduos sólidos um fator determinante para tal situação, devido ao elevando crescimento populacional e poucas práticas sustentáveis para a destinação (CAVALCANTE et al., 2012). Dessa forma, conhecer as práticas e atitudes da população é muito importante, Costa e Colesanti (2011), relatam que estudar a percepção ajuda a compreender e orientar ações sobre determinados espaços, além disso, a percepção e educação podem contribuir na diminuição da degradação ambiental (BELTRÃO, 2016).

Realizar o levantamento do que está ocorrendo no meio urbano é entender as relações sociais e de comportamento dos indivíduos, tendo em vista que estão interligadas diretamente com os problemas ambientais (SILVA et al., 2015). Sendo assim, a Educação Ambiental é de extrema importância no fortalecimento de práticas que visam a proteção do meio ambiente, principalmente no momento em que a sociedade está vivendo, do isolamento social em virtude da COVID-19, pois além de ajudar da proteção da natureza, as atitudes sustentáveis podem deixar o ambiente mais propício ao bem-estar social, amenizando o estresse recorrente (SILVA et al., 2020).

A percepção ambiental é de extrema importância na compreensão da relação entre o ser humano e o meio ambiente, fazendo com que os indivíduos expressem sua visão, satisfação e descontentamento sobre o meio em que está inserido (MELAZO, 2005). Diante desse contexto, o presente estudo teve como objetivo analisar a percepção ambiental e a produção de resíduos sólidos da população da Mesorregião Metropolitana de Belém, no Estado do Pará, durante o período de isolamento social, ocasionado pela COVID-19. 


\section{MATERIAL E MÉTODOS}

A presente pesquisa ocorreu na Mesorregião Metropolitana de Belém (MMB), a qual compreende onze municípios e localiza-se no Nordeste Paraense, nas coordenadas $1^{\circ} 03^{\prime} \mathrm{S}$ e $47^{\circ} 06^{\prime} \mathrm{W}$ a $1^{\circ} 85^{\prime} \mathrm{S}$ e $48^{\circ} 07^{\prime} \mathrm{W}$ (SANTOS et al., 2019), estando a cerca de 150 km da costa atlântica do Brasil (SANTOS et al., 2016). A MMB está localizada em um sítio de baixos plâtos e com pouca declividade, entremeado por vários igarapés, rios e baías, o qual a MMB apresenta fortes relações entre suas águas com a economia, o comercio e a cultura da região (PONTE et al., 2014).

As cidades utilizadas para a realização do trabalho foram: Ananindeua, Belém, Benevides, Castanhal, Marituba, Santa Izabel do Pará e Santa Bárbara do Pará (Figura 1), no qual juntas possuem uma área de aproximadamente $3.566,203 \mathrm{~km}^{2}$ e totalizam uma população estimada de 2.529.178 habitantes (IBGE, 2020).

Figura 1 - Mapa de localização das cidades da Mesorregião Metropolitana de Belém utilizadas na pesquisa
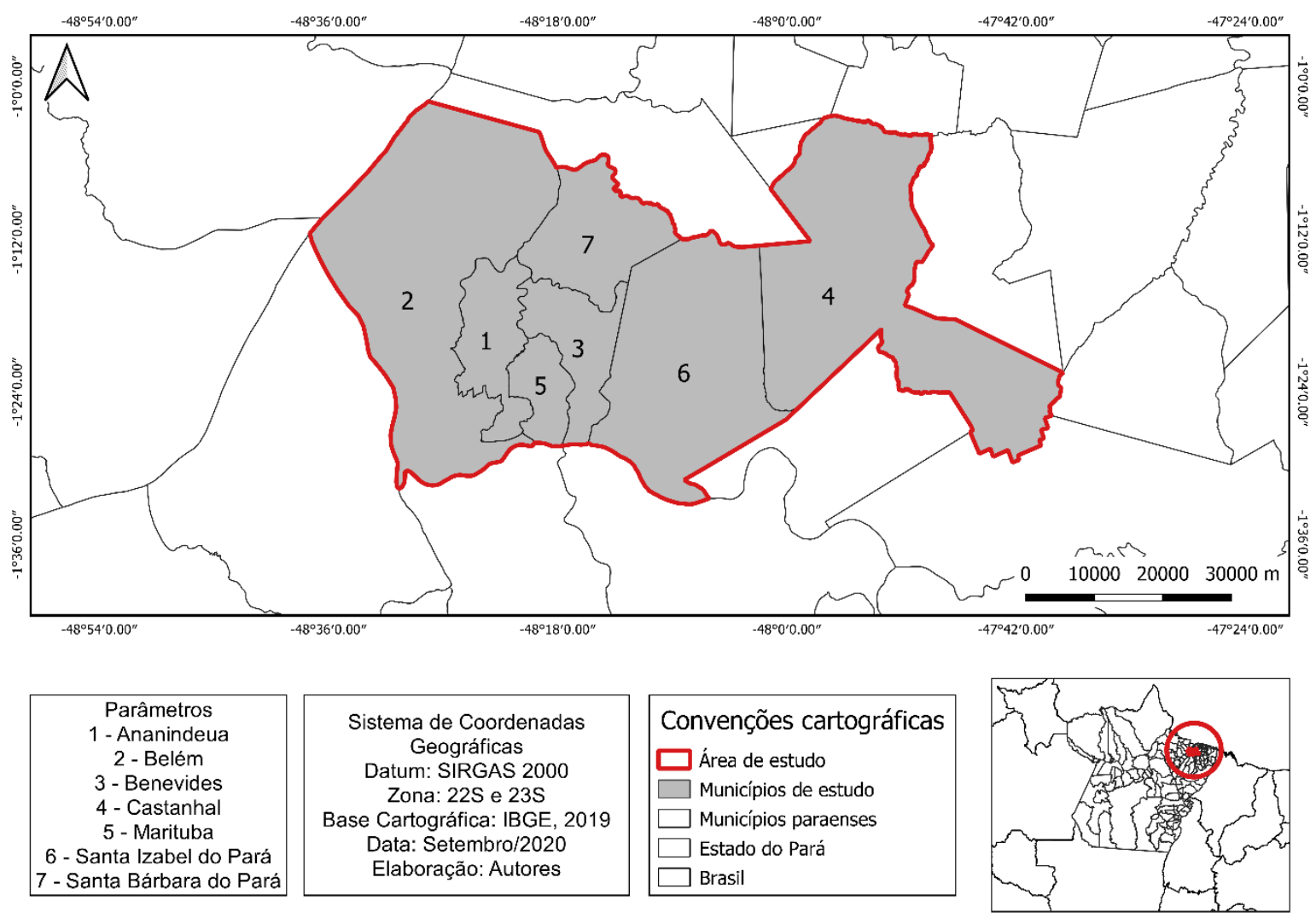

Fonte: Autores (2020) 
A pesquisa desenvolvida quanto a sua finalidade é caracterizada como pesquisa básica, a qual tem por objetivos o desenvolvimento de teorias, sendo uma das características dessa pesquisa a produção de artigos científicos (GARCES, 2010). Em relação aos seus objetivos, é uma pesquisa descritiva, pois esse tipo de pesquisa tem como principal objetivo descrever as características de uma população ou de algum fenômeno, tendo como delineamento de pesquisa o levantamento de campo, pois foi recolhida informações diretamente com as pessoas e dessa maneira, teve uma abordagem quantitativa, para conseguir chegar a conclusões em relação as coletas de dados e o tipo de amostragem utilizada foi a amostragem por cotas (GIL, 2008). A variável selecionada foi o município de residência, dessa forma, a amostragem total do trabalho está representada proporcionalmente pela quantidade de moradores de cada cidade que compõe a pesquisa.

A coleta de informações foi realizada por meio de questionário eletrônico (Google formulários), no período de 5 a 29 de agosto de 2020. O questionário foi construído com questões fechadas e ordenadas de acordo com a "Técnica de Funil" conforme descritos por Gil (2008). O questionário foi dividido em duas partes, onde a primeira era constituída de perguntas relacionadas à caracterização do perfil do participante (faixa etária, sexo, cidade, escolaridade) e na segunda, eram direcionadas a percepção do mesmo sobre o meio ambiente no período da pandemia do COVID-19 (Tabela 1).

Tabela 1 - Perguntas feitas aos participantes da pesquisa por meio do questionário eletrônico (Google Formulários)

\begin{tabular}{|c|c|}
\hline Perguntas & $\begin{array}{l}\text { Alternativas } \\
\end{array}$ \\
\hline 1. Faixa etária & $\begin{array}{l}\text { ( ) } 15 \text { até } 19 \text { anos; ( ) } 20 \text { até } 29 \text { anos; ( ) } 30 \text { até } 39 \\
\text { anos; ( ) } 40 \text { até } 49 \text { anos; ( ) } 50 \text { anos ou mais }\end{array}$ \\
\hline 2. Sexo & ( ) Feminino; ( ) Masculino; ( ) Outros \\
\hline 3. Cidade & $\begin{array}{l}\text { ( ) Ananindeua; ( ) Belém; ( ) Benevides; ( ) } \\
\text { Castanhal; ( ) Marituba; ( ) Santa Bárbara do Pará; } \\
\text { ( ) Santa Izabel do Pará }\end{array}$ \\
\hline 4. Escolaridade & $\begin{array}{l}\text { ( ) Ensino Fundamental Incompleto; ( ) Ensino } \\
\text { Fundamental Completo; ( ) Ensino Médio } \\
\text { Incompleto; ( ) Ensino Médio Completo; ( ) } \\
\text { Ensino Superior Incompleto; ( ) Ensino Superior } \\
\text { Completo. }\end{array}$ \\
\hline $\begin{array}{l}\text { 5. Para você a produção de resíduo na } \\
\text { sua cidade nesse período de } \\
\text { isolamento social: }\end{array}$ & () Aumentou; ( ) Diminuiu; ( ) Está a mesma coisa \\
\hline $\begin{array}{l}\text { 6. A coleta de lixo está acontecendo na } \\
\text { rua da sua casa nesse período de } \\
\text { isolamento social? }\end{array}$ & ( ) Sim, sempre; ( ) Sim, esporadicamente; ( ) Não \\
\hline
\end{tabular}


7. Nesse período de isolamento social, você está fazendo coleta seletiva na sua casa?

8. Ao realizar a coleta seletiva, você:

( ) Sim; ( ) Não

( ) Aciona alguma cooperativa para recolher os resíduos da sua casa; ( ) Entrega os resíduos recicláveis para os catadores de materiais recicláveis que passam nas ruas e o que não é reciclável é entregue para o serviço de coleta de lixo; ( ) Entrega tudo para o serviço de coleta de lixo; ( ) Não realizo coleta seletiva

9. Quais resíduos foram mais ( ) Plástico; ( ) Papel; ( ) Vidro; ( ) Metal; ( ) produzidos por você nesse período de isolamento social?

10. Você considera que políticas públicas de destinação de resíduos devem ser discutidas durante o período de pandemia?

11. Como você avalia o nível de poluição do meio ambiente nesse período de pandemia?

12. Você acha que a degradação do meio ambiente é um dos causadores da pandemia?

13. Para você, os resíduos sólidos produzidos em sua casa no período de isolamento social:

Eletrônicos (pilhas, baterias, carregadores, etc.); (

) Orgânico (resto de comida, casca de frutas, vegetais, etc.)

( ) Sim; ( ) Não

( ) Alto; ( ) Baixo; ( ) Igual

( ) Sim; ( ) Não

( ) Diminuíram; ( ) Aumentaram; ( ) Está a mesma coisa

Fonte: Autores (2020)

Foram respondidos um total de 524 questionários, contabilizando todas as 7 cidades escolhidas para o estudo, no qual o número mínimo de pessoas para responder foi previamente escolhido a partir do cálculo do tamanho da amostra calculada pela fórmula de Tagliacarne (1978). O resultado obtido é dado por (1).

$$
\begin{gathered}
n=\frac{N \times(z)^{2} \times p^{\prime} \times q^{\prime}}{(N-1) \times(E)^{2}+(z)^{2} \times p^{\prime} \times q^{\prime}} \\
n=\frac{2.529 .178 \times(1,96)^{2} \times 0,5 \times 0,5}{(2.529 .178-1) \times(0,05)^{2}+(1,96)^{2} \times 0,5 \times 0,5} \cong 385
\end{gathered}
$$

Onde:

$\mathrm{n}=$ Tamanho da amostra;

$\mathrm{N}=$ Número total de habitantes;

$\mathrm{z}=$ Intervalo de confiança

$\mathrm{E}=$ Erro amostral 
p' e q' = Proporção em que o fenômeno é esperado

A partir dos dados obtidos, foi realizada a tabulação e analises dos dados utilizando o software Excel, utilizando a estatística descritiva (porcentagem). A margem de erro utilizado na pesquisa foi de $5 \%$ para mais ou para menos, com um intervalo de confiança de $95 \%$.

\section{RESULTADOS E DISCUSSÃO}

A análise dos dados obtidos a partir da aplicação do questionário na Mesorregião Metropolitana de Belém (MMB), revelou que, do total de pessoas que responderam à pesquisa, $64,7 \%$ eram do sexo feminino, $34,9 \%$ masculino e $0,4 \%$ se declaram identificase com outra sexualidade, essa quantificação assemelhou-se à encontrada em um estudo feito por Querino e Pereira (2016), que evidenciou uma maior participação do público feminino, cerca de $57 \%$.

As respostas ao questionário foram predominantes de pessoas que compreendem a faixa etária de 20 a 29 anos $(39,1 \%)$, isso pode está relacionado a um maior interesse do grupo em responder o questionário e a maior facilidade com a utilização da plataforma. Os demais resultados foram, como demostrado na Figura 2, 11,1\% estavam na faixa etária de 15 a 19 anos, $20,4 \%$ entre 30 e 39 anos, $13 \%$ de 40 a 49 anos e $16 \%$ com idade igual ou maior a 50 anos.

Figura 2 - Respostas dos participantes para a pergunta "Distribuição dos participantes quanto à faixa etária"

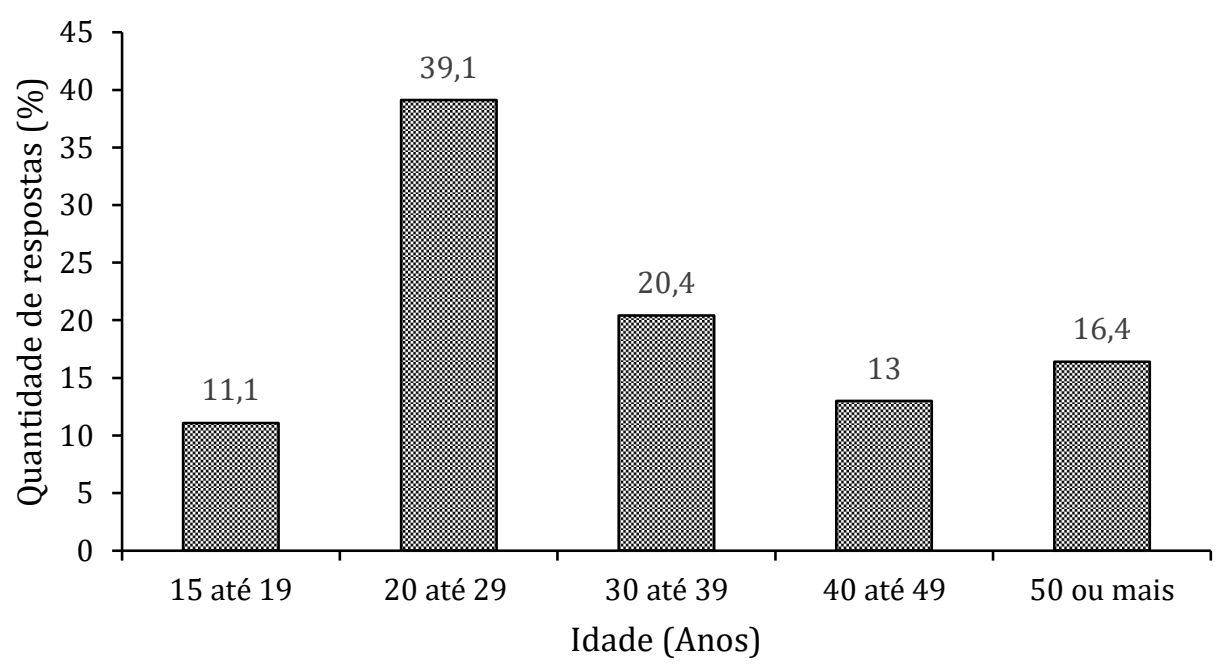


Para o nível de escolaridade (Figura 3), houve participação predominante de pessoais com ensino superior completo, incompleto e ensino médio completo, respectivamente $32,6 \%, 28,8 \%$ e $24 \%$, os demais níveis, ensino médio incompleto, fundamental completo e fundamental incompleto, alcançaram os seguintes percentuais, $6,1 \%, 2,1 \%$ e $6,3 \%$, o que pode representar uma população amostral mais crítica em relação ao assunto abordado (BARRETO et al., 2008).

Figura 3 - Respostas dos participantes para a pergunta "Distribuição dos participantes quanto ao nível de escolaridade"

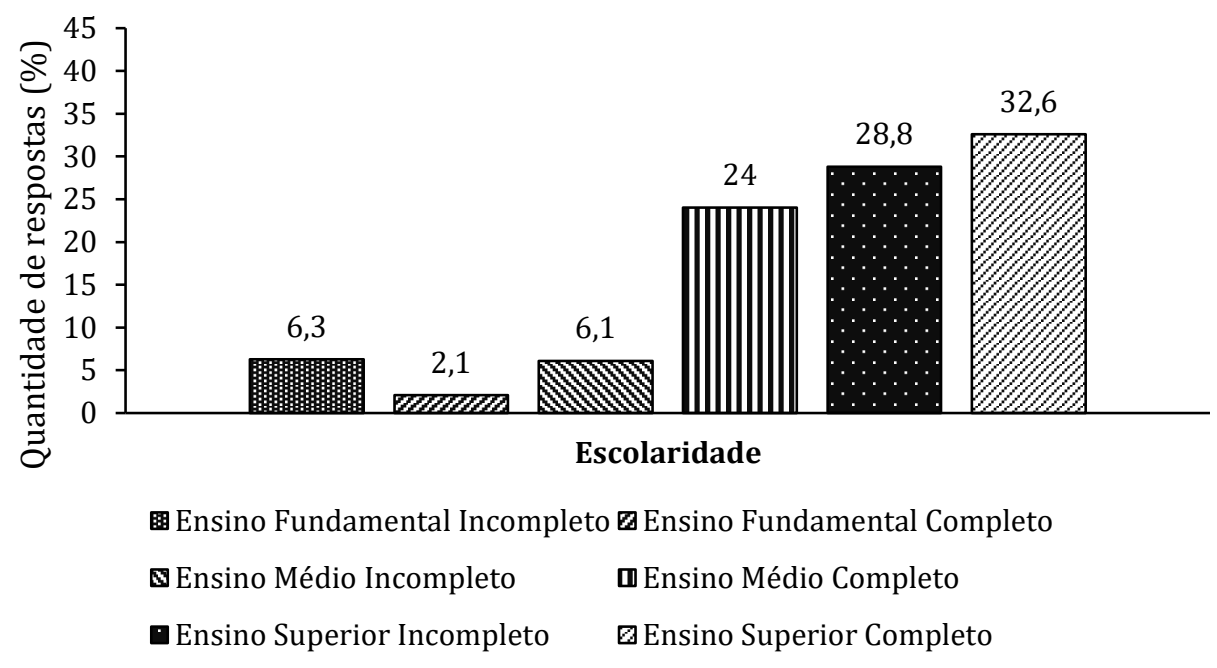

Fonte: Autores (2020)

$\mathrm{Na}$ visão da maior parte dos participantes, a produção de resíduo aumentou durante o período de isolamento pela Covid-19, representando 60,5\%, a alternativa "Está a mesma coisa" representou $24,2 \%$ do total de respostas, sendo mais frequente a de "Diminuiu" 12,4\%. Considerando as respostas por cidade (Figura 4), observa-se que, a percepção de aumento e estagnação foi predominante em quase todos os municípios da região metropolitana, com exceção para Marituba, que a resposta "Diminuiu" superou a "Está a mesma coisa" em retornos, com respectivamente 1,3\% e 0,8\% do total de participantes. Entretanto, observa-se que a percepção dos moradores da região metropolitana reflete na estimativa da ABRELPE (2020a), que espera o aumento na produção de resíduos sólidos domiciliares em decorrência do período de emergência sanitária no Brasil. 
Figura 4 - Respostas dos participantes para a pergunta "Para você a produção de resíduo na sua cidade nesse período de isolamento social"

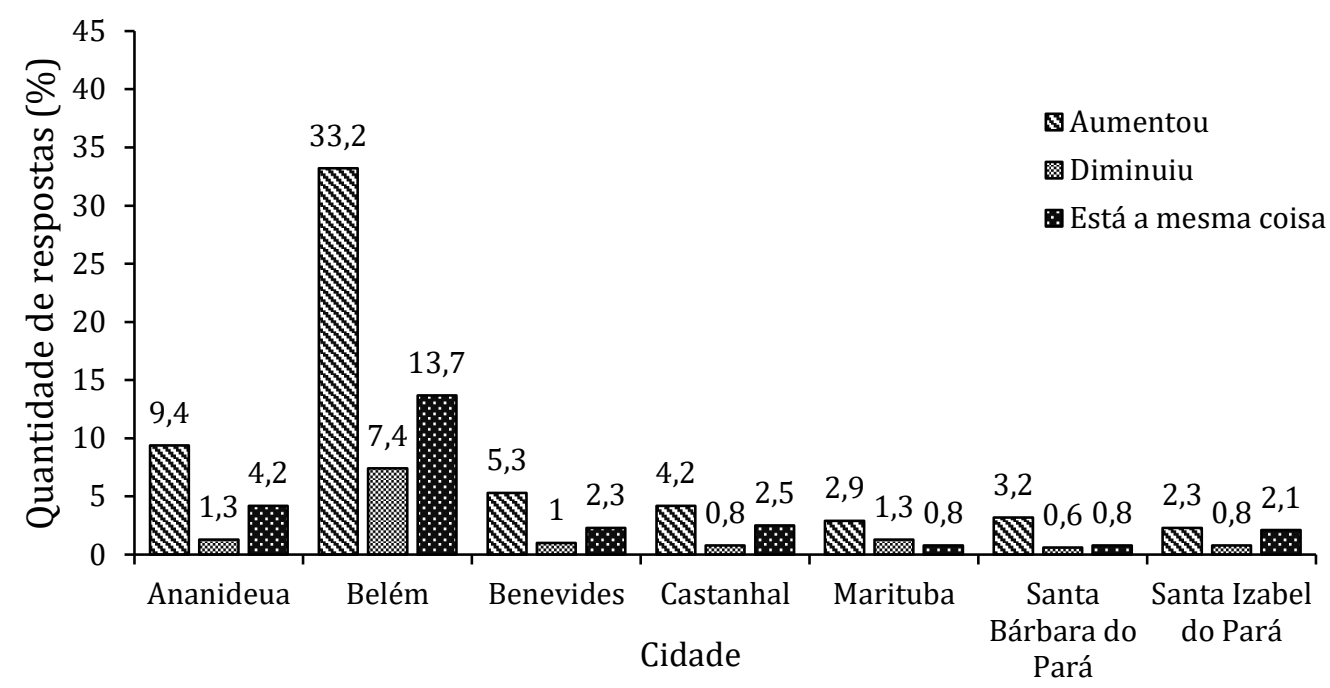

Fonte: Autores (2020)

Sobre a pergunta "A coleta de lixo está acontecendo na rua da sua casa nesse período de isolamento social?", $395(75,4 \%)$ dos participantes da pesquisa afirmaram que a coleta acontece sempre, $110(21,0 \%)$ pessoas responderam que ela ocorre esporadicamente, e 19 (3,6\%) que não há coleta, índice próximo do verificado pelo IVS (2017), onde mais de 90\% dos domicílios da RMB são contemplados pelo recolhimento dos resíduos e cerca de 2,45\% não são. Quando se observa o resultado por município (Figura 5), as respostas seguem o mesmo padrão para Ananindeua, Belém, Benevides e Castanhal, onde a alternativa "sim, sempre" foi superior as demais, seguida pela resposta "sim, esporadicamente", ainda, poucos participantes responderam que a coleta de lixo não está acontecendo normalmente, em Ananindeua nenhum respondeu a alternativa “não", em Belém 0,8\%, Benevides e Castanhal 0,2\% do total de participantes. Para Marituba, os participantes, em sua maioria (2,9\%), responderam que a coleta ocorre esporadicamente e 2,1\% que é realizada sempre. Em Santa Bárbara do Pará, 2,5\% responderam "sim, sempre", $0,4 \%$ esporadicamente e $1,7 \%$ responderam que a coleta não está ocorrendo e por último no município de Santa Izabel do Pará, a maioria dos participantes responderam que a coleta ocorre sempre, representando $4,2 \%$ do total de resposta, $0,2 \%$ que ocorre esporadicamente e $0,8 \%$ que não ocorre.

Figura 5 - Respostas dos participantes para a pergunta "A coleta de lixo está acontecendo na rua da sua casa nesse período de isolamento social?" 


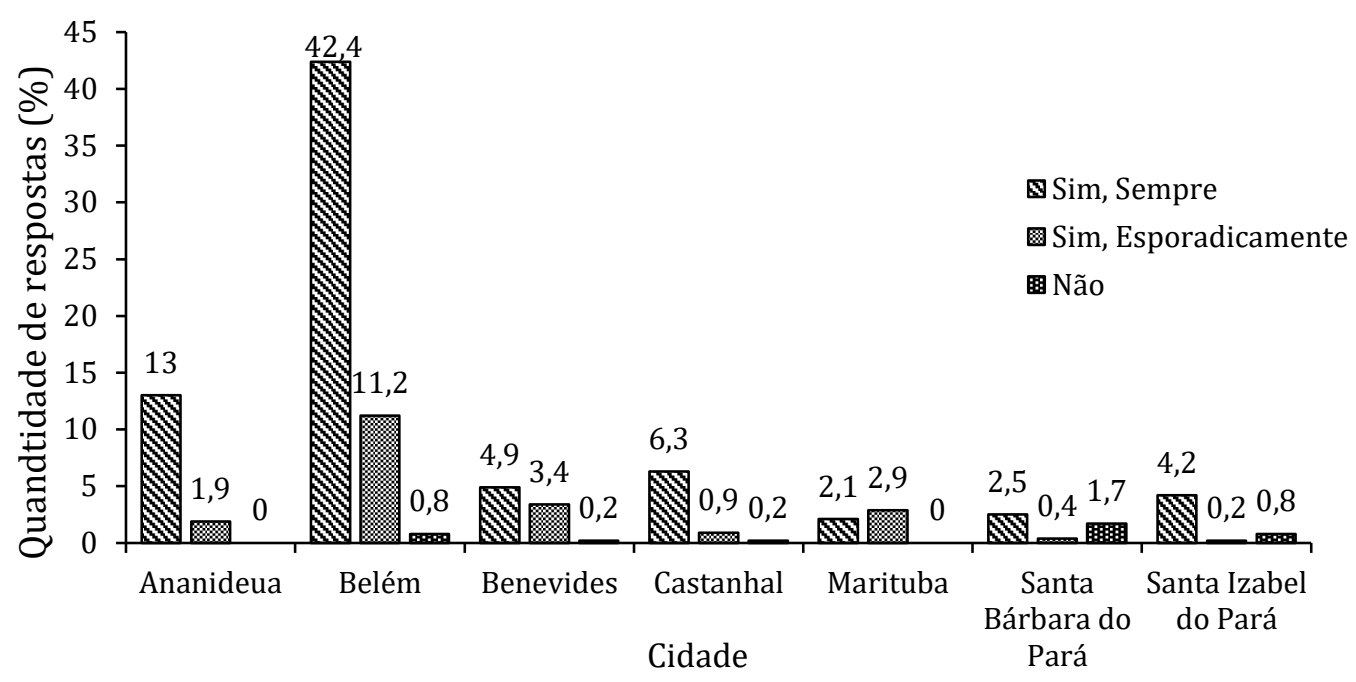

Fonte: Autores (2020)

Observa-se que ao indagar se no período de isolamento social os participantes fizeram coleta seletiva, notou-se que 50,2\% dos entrevistados responderam "Não" e 49,8\% "Sim", mostrando que durante a pandemia quase 50\% realizaram a separação de algum resíduo, corroborando com o posicionamento das entidades representativas do setor de resíduos sólidos no brasil para gestão de resíduos contra o coronavírus (covid 19) vinculadas à ABRELPE (2020b) que indicou um aumento na coleta seletiva em todas as regiões brasileiras a partir de dados obtidos entre 15 de março e 17 de abril de 2020 . Na figura 6, pode-se ressaltar que, apesar dos dados gerais demonstrarem que o percentual de entrevistados que não praticam coleta seletiva ser maior que os praticantes, nos municípios de Ananindeua, Belém, Benevides e Marituba, a resposta positiva, representou $7,8 \%, 27,9 \%, 5,7 \%, 2,7 \%$ do total de participantes respectivamente, e esses valores foram maiores em relação as repostas negativas para essas cidades. Nas demais cidades, os que não fizeram seleção no descarte de resíduos foram majoritários em comparação aos que praticaram, Castanhal obteve "Sim" em 2,9\% e 4,6\% "Não", Santa Bárbara do Pará 0,6\% para "Sim" e 4\% para "Não" e Santa Izabel do Pará 2,3\% e 2,9\% para as repostas "Sim" e "Não", respectivamente.

Figura 6 - Respostas dos participantes para a pergunta "Nesse período de isolamento social, você está fazendo coleta seletiva na sua casa?" 


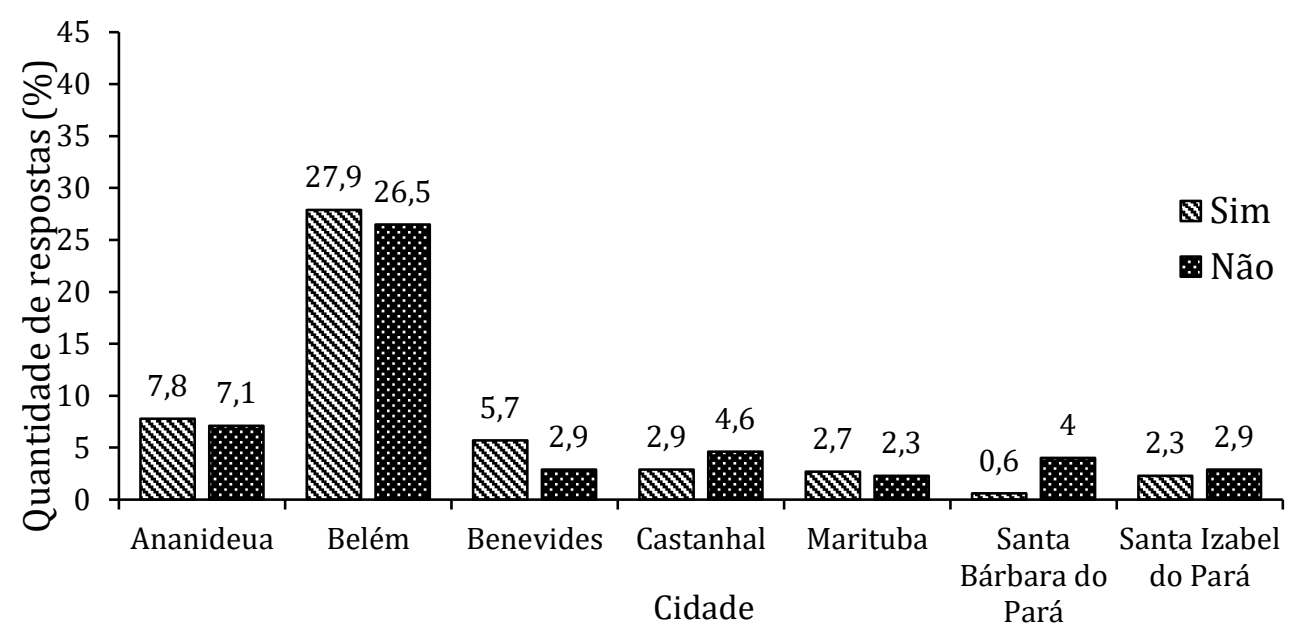

Fonte: Autores (2020)

Aos que responderam que "Sim" na pergunta supracitada, foi questionado qual o fim é concedido ao resíduo (Figura 7), para os 261 participantes que marcaram essa alternativa, 44,4\% responderam que entregam tudo para o serviço de coleta de lixo local, o qual não tem seleção dos resíduos, 47,9\% selecionaram a opção "Entrega os resíduos recicláveis para os catadores de materiais recicláveis que passam nas ruas e o que não é reciclável é entregue para o serviço de coleta de lixo" e apenas 7,7\% afirmaram que acionam cooperativas de reciclagem para recolher o resíduo de sua casa. Além disso, Farias (2019) observou que 32,8\% dos seus entrevistados responderam não ao serem indagados sobre se procuravam pontos de coletas de materiais recicláveis, evidenciando a falta de conhecimento acerca das cooperativas que atuam na área, pois algumas coletam à domicílio, através dos seus associados.

Figura 7 - Respostas dos participantes para a pergunta "Ao realizar a coleta seletiva, você:"

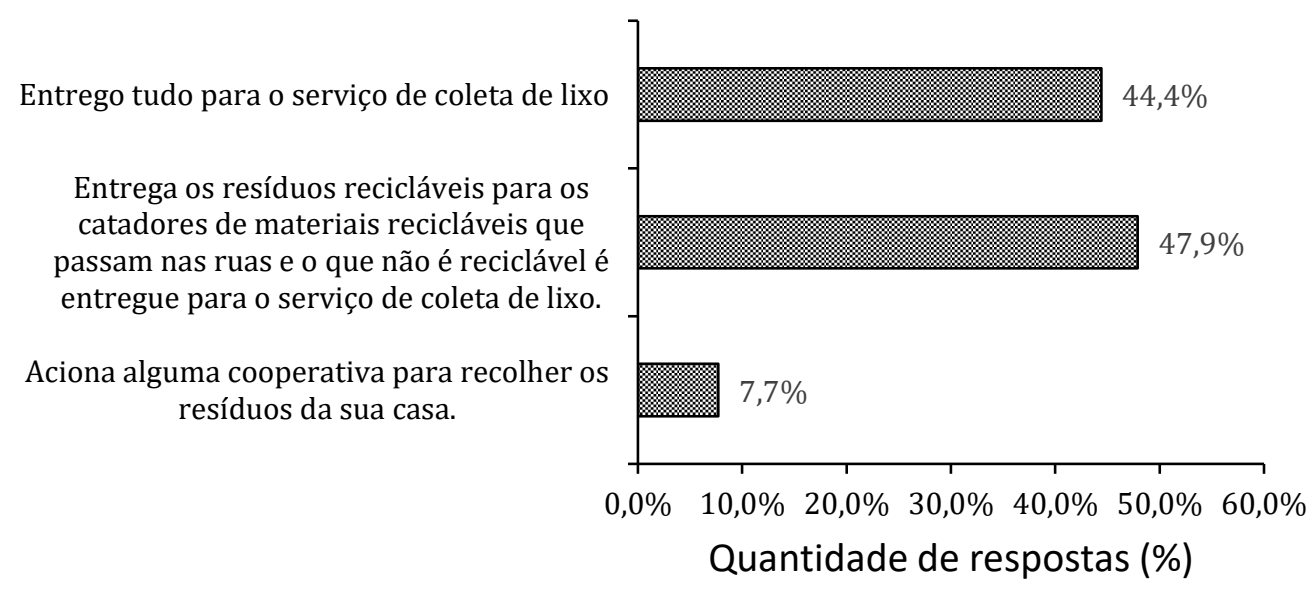


Na tabela 2 está apresentado as respostas da pergunta "Quais resíduos foram mais produzidos por você nesse período de isolamento social?”, 44,8\% dos participantes notaram que a sua produção de resíduos orgânicos foi superior em comparação com os outros objetos apresentados, 41,2\% dos entrevistados afirmam que o plástico foi o material mais descartados durante a quarentena, essas alternativas denotam a maioria dos 524 retornos, as outras opções, papel, vidro, metal e eletrônicos obtiveram, respectivamente, $10,1 \%, 1 \%, 1,5 \%$ e $1,3 \%$. O que foi encontrado por Pinheiro (2018), que ao pesquisar sobre a percepção ambiental dos moradores de um bairro de Belém, notou que os residentes atestaram que $56 \%$ dos resíduos produzidos são inorgânicos. Além disso, a Prefeitura Municipal de Belém (2020), em seu plano municipal de saneamento básico, intitulado "Situação dos serviços de limpeza urbana e manejo de resíduos sólidos, revisão 2", apontou que, em 2019, 51,34\% da composição gravimétrica resumida dos resíduos domiciliares foram orgânicos e 25,94\% de materiais recicláveis, demonstrando o mínimo de mudança em comparação aos resultados do presente trabalho.

Quando observado no âmbito dos municípios estudados, para os moradores de Ananindeua, Belém, Castanhal e Marituba o descarte de produtos orgânicos foi superior ao demais, constata-se que para essas cidades, o plástico foi o segundo resíduo mais produzindo seguido do papel, com exceção de Castanhal, que papel $(1,9 \%)$ foi maior à plástico (1,5\%) em número de respostas. Porém, em Benevides, Santa Bárbara do Pará e Santa Izabel do Pará, os residentes responderam que o plástico, acompanhado do lixo orgânico e do papel foram os mais descartados durante o isolamento, vidro, metal e eletrônicos foram pouco mencionados pelos participantes, não obtendo nenhum retorno em alguns municípios.

Tabela 2: Respostas dos participantes para a pergunta "Quais resíduos foram mais produzidos

\begin{tabular}{c|c|c|c|c|c|c}
\multicolumn{6}{c}{ por você nesse período de isolamento social?"” } \\
\hline \multirow{2}{*}{ Cidades } & \multicolumn{5}{|c}{ Tipos de resíduos } \\
\cline { 2 - 7 } & Plástico & Papel & Vidro & Metal & Eletrônicos & Orgânicos \\
\hline Ananindeua & $5,3 \%$ & $2,3 \%$ & $0,0 \%$ & $0,19 \%$ & $0,2 \%$ & $6,9 \%$ \\
\hline Belém & $21,8 \%$ & $4,8 \%$ & $0,4 \%$ & $0,38 \%$ & $0,6 \%$ & $26,5 \%$ \\
\hline Benevides & $4,8 \%$ & $0,4 \%$ & $0,0 \%$ & $0,00 \%$ & $0,0 \%$ & $3,4 \%$ \\
\hline Castanhal & $1,5 \%$ & $1,9 \%$ & $0,2 \%$ & $0,19 \%$ & $0,2 \%$ & $3,4 \%$ \\
\hline
\end{tabular}




\begin{tabular}{c|c|c|c|c|c|c} 
Marituba & $1,7 \%$ & $0,2 \%$ & $0,4 \%$ & $0,19 \%$ & $0,4 \%$ & $2,1 \%$ \\
\hline Santa Bárbara do Pará & $2,7 \%$ & $0,4 \%$ & $0,0 \%$ & $0,00 \%$ & $0,0 \%$ & $1,5 \%$ \\
\hline Santa Izabel do Pará & $3,4 \%$ & $0,2 \%$ & $0,0 \%$ & $0,57 \%$ & $0,0 \%$ & $1,0 \%$ \\
\hline Total & $41,2 \%$ & $10,1 \%$ & $1,0 \%$ & $1,5 \%$ & $1,3 \%$ & $44,8 \%$ \\
\hline
\end{tabular}

Fonte: Autores (2020)

No questionamento "Você considera que políticas públicas de destinação de resíduos devem ser discutidas durante o período de pandemia?" (Figura 8), dos 524 participantes, $491(93,7 \%)$ responderam que políticas voltadas a administração de resíduos precisam ser debatidas mesmo no contexto pandêmico provocado pelo coronavírus, $33(6,3 \%)$ acreditam que, no atual momento, não devem ser discutidos. Resultado satisfatório, quando comparado com Farias (2019) que questionou sobre a participação das prefeituras nas ações de conscientização da população e obteve resposta negativa de $30,7 \%$ dos entrevistados.

Figura 8 - Respostas dos participantes para a pergunta "Você considera que políticas públicas de destinação de resíduos devem ser discutidas durante o período de pandemia?"

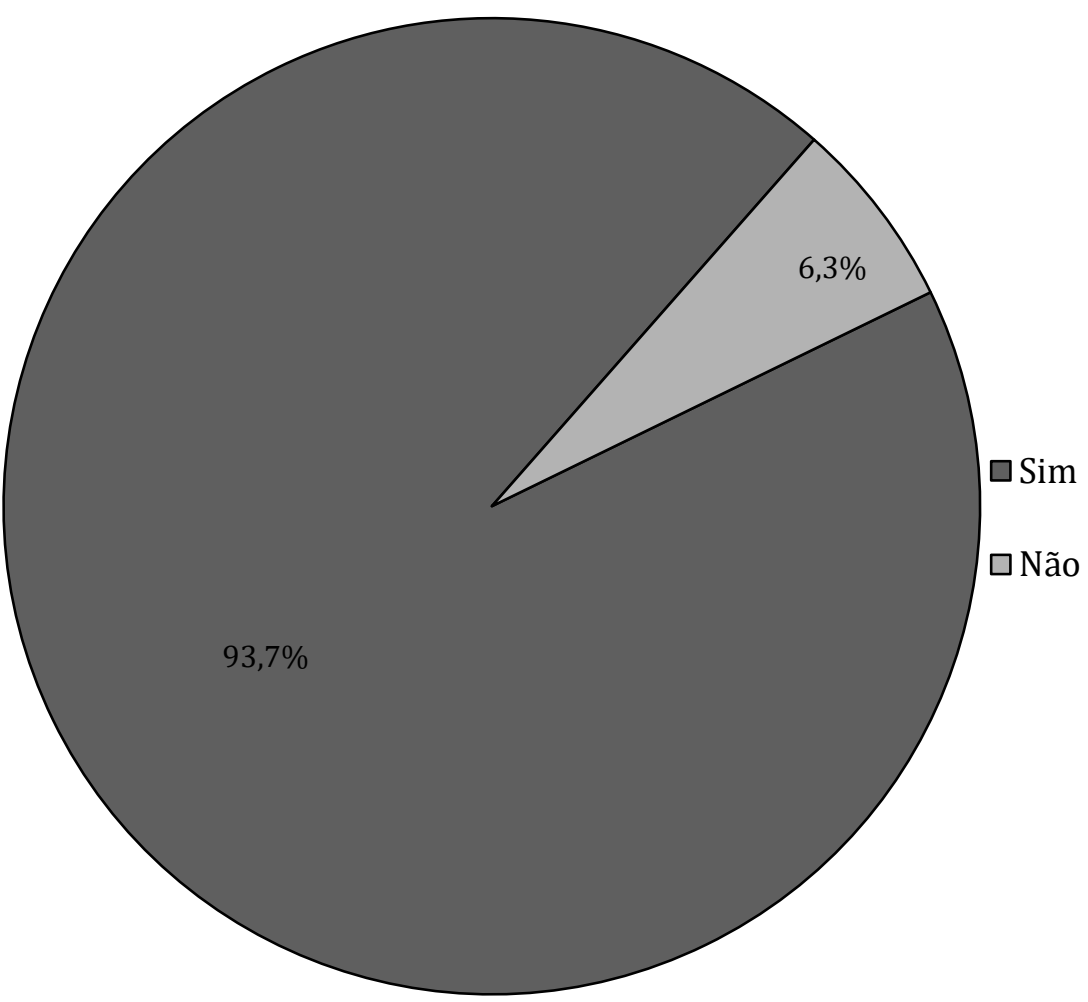

Fonte: Autores (2020) 
Para pergunta "Como você avalia o nível de poluição do meio ambiente nesse período de pandemia?", foi constatado que 52,3\% participantes consideram que a poluição aumentou na região metropolitana durante a pandemia, 19,1\% avaliam que abaixou e 28,6\% não perceberam diferença no nível de poluição para com o período anterior a pandemia, assim como Farias (2019) que quantificou a percepção dos moradores da RMB, cerca de 41,1\% dos entrevistados avaliaram com um elevado nível de danos ao meio ambiente. Ao avaliar a distribuição por cidade pesquisada, verifica que em quase todos os municípios as alternativas que mais obtiveram retorno foram "alto" e “igual”, como observado na figura 9, apenas para os participantes de Benevides houve mais retornos do "baixo" se comparado com o "igual".

Figura 9 - Respostas dos participantes da pesquisa para a pergunta "Como você avalia o nível de poluição do meio ambiente nesse período de pandemia?"

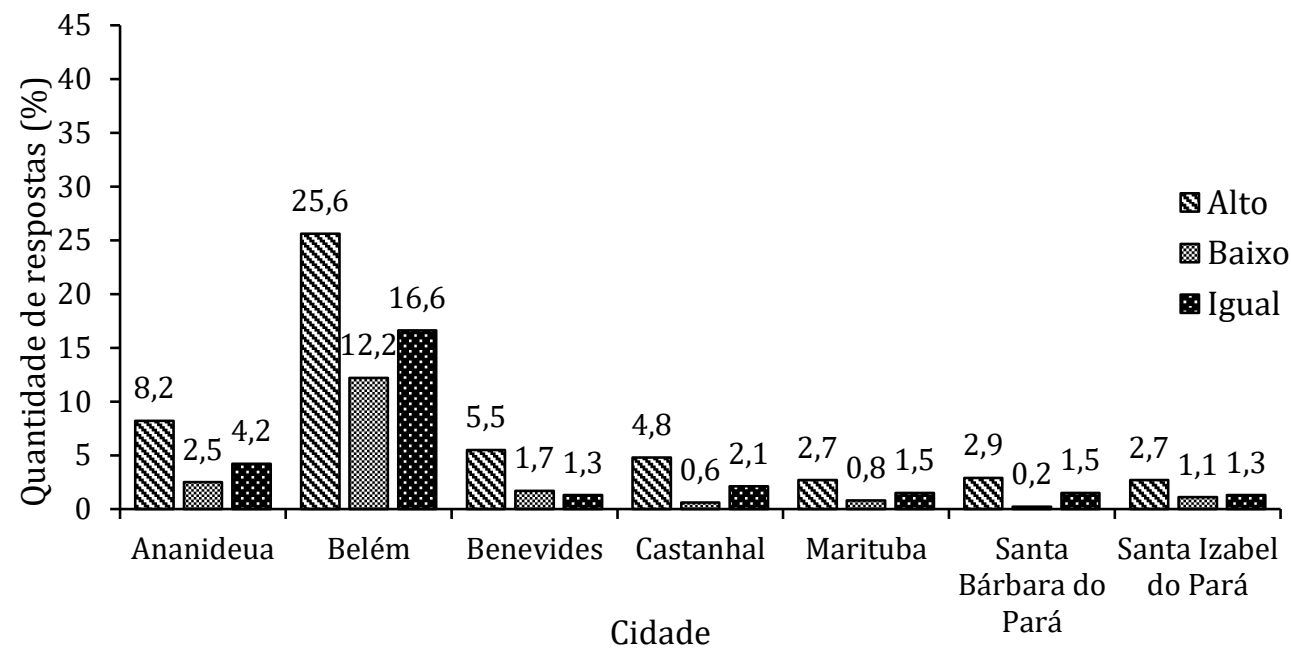

Fonte: Autores (2020)

$\mathrm{Na}$ indagação "Você acha que a degradação do meio ambiente é um dos causadores da pandemia?" (Figura 10), 273 (52,1\%) entrevistados responderam que não consideram que a degeneração foi determinante para pandemia de covid-19, contudo, 251 $(47,9 \%)$ acreditam que o distúrbio ambiental foi um fator decisivo para que houvesse a disseminação mundial do vírus, demonstrando equilíbrio entre as opiniões da população da MMB. Esse debate vem sendo discutido como mencionado por Lindahl e Grace (2015) e Lima (2020), que associam mudanças climáticas, do uso da terra e da água e urbanização com surgimentos de doenças infecciosas, exemplificando estudos produzidos que apontam o contato humano com animais como principais responsáveis por epidemias e 
pandemias, esses processos levantam hipóteses do surgimento e potencialidade de surtos causados por doenças infecciosas.

Figura 10 - Respostas dos participantes das pesquisas para a pergunta "Você acha que a degradação do meio ambiente é um dos causadores da pandemia?"

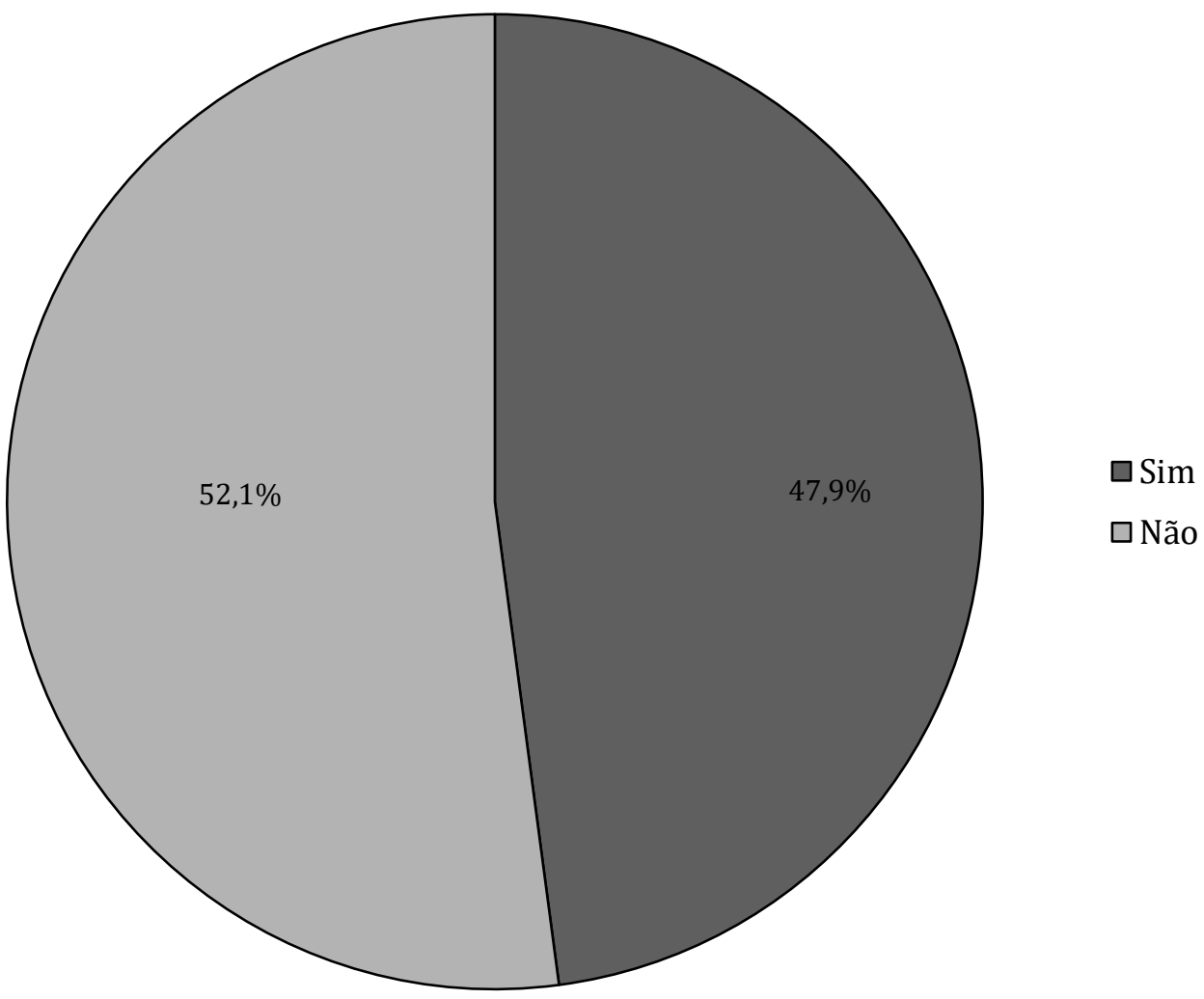

Fonte: Autores (2020)

Quando questionado sobre a produção de resíduos sólidos em sua casa (Figura 11), $46,2 \%$ dos entrevistados responderam que aumentaram durante o período de isolamento social, 41,6\% acreditam que o lixo doméstico de sua residência não variou com a quarentena e 12,2\% declaram que diminuíram. Na maioria dos municípios estudados, observa o mesmo comportamento, onde as alternativas com maiores retornos são as "Aumentaram" e "Está a mesma coisa", sendo a primeira maior no município de Belém e Santa Bárbara do Pará, os que afirmam que houve estagnação da produção de resíduos foram maiores que as demais em Benevides, Castanhal e Marituba. Em Ananindeua, a quantidade de participantes que responderam "Aumentaram" e "Está a mesma coisa" foi igual, representando $6,9 \%$ do total da amostragem, a opção "Diminuíram" se igualou a aumentaram somente no município de Santa Izabel do Pará. 
Figura 11 - Respostas dos participantes das pesquisas para a pergunta "Para você, os resíduos sólidos produzidos em sua casa no período de isolamento social"

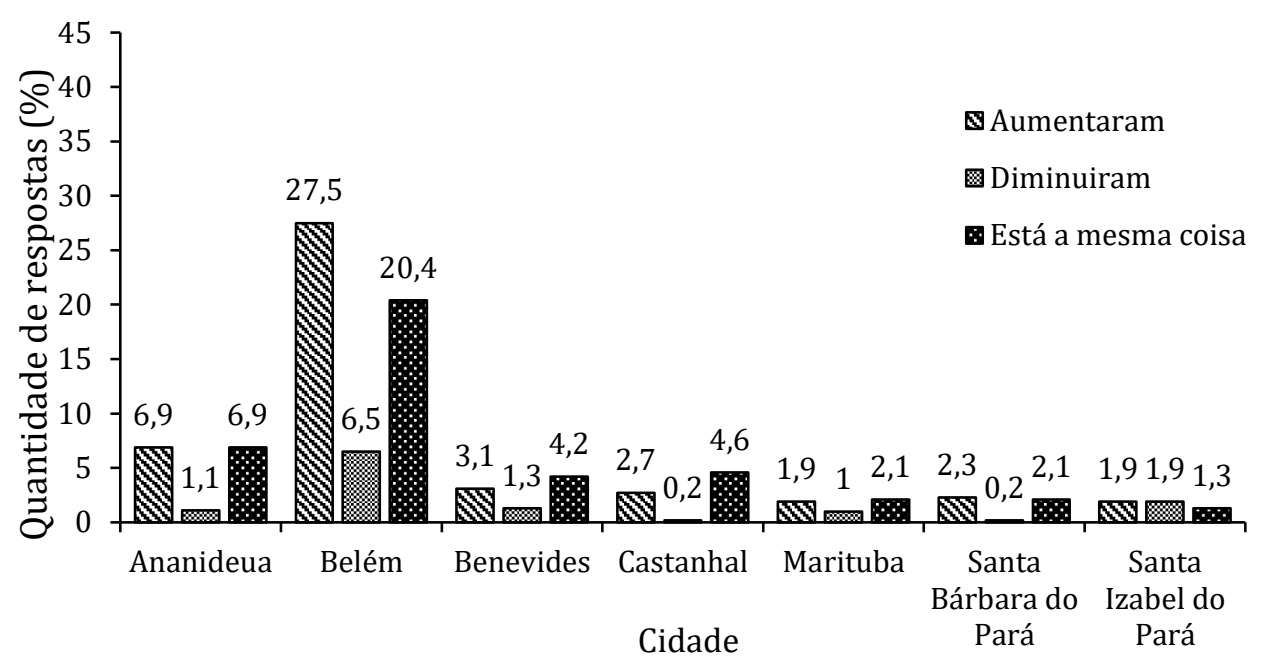

Fonte: Autores (2020)

\section{CONCLUSÃO}

Por meio da pesquisa realizada, os moradores da MMB, tiveram a percepção que houve o aumento da produção de resíduos sólidos durante o período da pandemia, além de que, os resíduos mais produzidos foram os orgânicos e plásticos.

Diante disso, nota-se que trabalhos como esse, são importantes para conhecer a percepção da população acerca da produção de resíduos sólidos, e com isso é possível que sejam realizados atividades e projetos que promovam a educação ambiental. Além disso, informações como essas obtidas, podem auxiliar na melhor gestão das coletas seletivas do lixo e com isso promover a preservação do meio ambiente e a qualidade de vida da população nesse período de pandemia.

\section{REFERÊNCIAS}

ABRELPE. Recomendações para a gestão de resíduos sólidos durante a pandemia de coronavírus (covid-19), 2020a. Disponível em: <https://abrelpe.org.br/abrelp-nocombate-a-covid-19/> Acesso em: 15.12. 2020.

ABRELPE. Posicionamento das entidades representativas do setor de resíduos sólidos no brasil para gestão de resíduos contra o coronavírus (covid 19), 2020b. Disponível em: <https://abrelpe.org.br/abrelpe-no-combate-a-covid-19/> Acesso em: 25.05.2021. 
Atlas da vulnerabilidade social. Porcentagem dos municípios que são contemplados e não completados com a coleta de resíduos sólidos 1, 2017 Disponível em: <http://ivs.ipea.gov.br/index.php/pt/planilha>. Acesso em: 13.12.2020.

BARRETO, Luciano et al. Análise ambiental e social do bairro São Domingos em Ilhéus-Bahia. Enciclopédia Biosfera, v. 4, n. 6, 2008

BELTRÃO, M. R. M, et al. Percepção ambiental sobre a gestão de resíduos sólidos: estudo de caso do conjunto residencial Pernambuco. Gestão e Sustentabilidade Ambiental, v. 4, n.2, p.209-233, 2016.

CAVALCANTE, L. P. S; CAVALCANTE, L.S; MEDEIROS, V. S; MAIA, H. J. L; ALENCAR, L. D. Análise da Percepção Ambiental e Sensibilidade de Educandos do Ensino Fundamental de uma Escola Pública para Realização da Coleta Seletiva, Campina Grande - PB. Monografias Ambientais. v.9, nº 9, p. 2047 - 2054, 2012.

COSTA, R.G.S.; Colesanti, M.M. A contribuição da percepção ambiental nos estudos das áreas verdes. RA'E GA, v. 22, p. 238-251, 2011.

FARIAS, M. F. S. Sustentabilidade e meio ambiente: a percepção dos moradores da região metropolitana de Belém, Pará, Amazônia, Brasil, 2019. Biblioteca Digital de Trabalhos Acadêmicos da Universidade Federal Rural da Amazônia (BDTA/UFRA). Disponível em: bdta.ufra.edu.br/jspui//handle/123456789/1009. Acesso: 14.12.2020.

GARCES, S. B. B. Classificação e tipos de pesquisas. Universidade de Cruz AltaUnicruz, 2010.

GIL, A. C. Métodos e técnicas de pesquisa social. 6. ed. Editora Atlas SA, 2008.

INSTITUTO BRASILEIRO DE GEOGRAFIA E ESTATISTICA. Dados por

Cidades. Disponível em: <http://www.cidades.ibge.gov.br/brasil/pa/panorama>. Acesso em: 18. 06. 2020.

LINDAHL, J. F.; GRACE, D. The consequences of human actions on risks for infectious diseases: a review. Infection Ecology \& Epidemiology, 5, 1, p. 1-11, 2015.

LIMA, C. E. P. As mudanças ambientais e a saúde humana: impactos da degradação ambiental sobre surtos de doenças infecciosas, 2020. Disponível em:<https://www.embrapa.br/busca-de-noticias/-/noticia/52769086/artigo---asmudancas-ambientais-e-a-saude-humana-impactos-da-degradacao-ambiental-sobresurtosdedoencasinfecciosas\#: :text=As\%20mudan\%C3\%A7as\%20ambientais\%20antropog\% C3\%AAnicas\%20tamb\%C3\%A9m,et\%20al.\%2C\%202015)> Acesso: 25.05.2021

MELLAZO, G.C. A percepção ambiental e educação ambiental: uma reflexão sobre as elações interpessoais e ambientais no espaço urbano. Olhares \& Trilhas. Uberlândia, Ano VI, n. 6, p. 45-51, 2005. 
OPAS/OMS. Organização Pan-Americana da Saúde/Organização Mundial da Saúde. Folha informativa-COVID-19(doença causada pelo novo coronavírus). Disponível em: < https://www.paho.org/pt/covid19>. Acesso em: 10. 12. 2020.

PINHEIRO, C. P. S. Diagnósticos e proposições sobre a questão dos resíduos sólidos no conjunto catalina, bairro do mangueirão, Belém-PA, 2018. Educação Ambiental em Ação, Novo Hamburgo, v. 17, n. 64, p. 1, jun./ago. 2018. Disponivel em: http://revistaea.org/artigo.php?idartigo=3241. Acesso em: 15.12. 2020.

PONTES, J. P. X.; et al. Urbanização de assentamentos precários na Região Metropolitana de Belém: problemas de desenho e infraestrutura urbana. Práticas recentes de intervenções contemporâneas em cidades da América Latina, 2014.

PREFEITURA MUNICIPAL DE BELÉM. Plano Municipal De Saneamento Básico, Belém/PA. Belém, 2020. Disponível em: < http://ww4.belem.pa.gov.br/wpcontent/uploads/2020/10/Diagn\%C3\%B3stico-T\%C3\%A9cnico-Participativo$\%$ E2\%80\%93-Relat\%C3\%B3rio-3.5.pdf>. Acesso em: 25.05.2020.

QUERINO, L. A. L.; PEREIRA, J. P. G. Sustentabilidade Em Instituições De Ensino Superior. Revista Monografias Ambientais, v. 15, n. 1, p. 404-415, 2016.

SANTOS, M. R. S.; et al. Padrões de precipitação mensal na mesorregião metropolitana de Belém: uso do CMORPH e componentes principais. Revista Brasileira de Geografia Física, v. 9, n. 7, p. 2301-2311, 2016.

SANTOS, M. R. S.; et al. Identificação de extremos de chuva na mesorregião metropolitana de Belém: o uso do modelo box plot para a gestão socioambiental. Revista Brasileira de Geografia Física, v. 12, n. 04, p. 1554-1562, 2019.

SILVA, D. S. C, et al. Impactos Causados pela Covid-19: um Estudo Preliminar. Revbea, São Paulo, V. 15, No 4: 128-147, 2020.

SILVA, M. P, et al. Análise da Influência dos Aspectos Sociais na Percepção Ambiental da População Residente na Microbacia do Córrego do Mineirinho, Município de São Carlos-SP. Revista EIXO, Brasília-DF, v. 4, n. 2, julho-dezembro de 2015.

TAGLIACARNE, G. Pesquisa de Mercado: técnica e prática. São Paulo: Atlas, 1978, pg. 173.

Recebido em: 20/11/2021

Aprovado em: 15/12/2021

Publicado em: 18/12/2021 